\title{
Dynamics of the content plastid pigments in leaves of plants of hybrids F1 of tomato (Lycopersicon esculentum Mill.) depending on propagation and growth of plants
}

\author{
N. Giptenko,
}

A. Likhanov, Candidate of Biological Sciences

National University of Bioresources and Natural Resources of Ukraine

The purpose. To study dynamics of the content of chlorophyll pigments $a$ and $b$ and carotenoids $k$ in leaves of tomato (Lycopersicon esculentum Mill.) in perspective hybrids: KDS-5 F1 (k), Enei F1, Barmalei F1, Pobratim F1, Yatran F1, Veselka F1 during vegetation in master phases of growth (budding, blooming, fruit brearing) in conditions of film glasshouses. Methods. Laboratory, vegetation, measuring-weighting, biochemical, mathematical-statistical. Results. Features of operation of pigment system of hybrids F1 of tomato depending on conditions of growing of seedling in cartridges in glass-covered ground are analyzed. Phase dynamics of the content of plastid pigments and carotenoids in conditions of film glasshouses is fixed. Indexes of pigment content in leaves of hybrid Barmalei F1, Pobratim F1, Yatran F1 are higher in comparison with other probed hybrids F1 of tomato. Conclusions. The best method of growing of seedling is use of cartridges. It is shown that the quantitative content of plastid pigments in leaves of probed crop (Lycopersicon esculentum Mill.), cultivated in film glasshouse on solar heating, - is average. It is fixed that indexes of pigment content in leaves of hybrids Barmalei F1, Pobratim F1, Yatran F1 is higher in comparison with other probed hybrids F1. That can testify to high adaptive potential of these hybrids for conditions of film glasshouse.

Key words: cartridges, chlorophyll pigments $a, b$ and carotenoid $k$, leaf, hybrid $F 1$.

Introduction. We know that the main source of plastic substances necessary for growth and development of the plant organism is photosynthesis $[1,2,4,10]$. The productivity of plants is largely determined by the level of accumulation of assimilating organs plastydnyh pigments. The content of pigments, and the ratio between them is leaf physiological characteristics [2, 4, 6, 8]. In recent years formed an idea of the direction dependence of photosynthesis and productivity of the factors, including the method of growing seedlings that may significantly affect the chlorophyll content and their functional activity. Therefore, the study of the dynamics of accumulation of chlorophyll in the leaves of tomato plants by biological factors is important because they affect the content rate of photosynthesis and other physiological processes [1, 4, 9, 12]. May be important reasons for the decline of chlorophyll content, disease, lack of trace elements, normal aging process leaves chlorosis. Chlorotic spots on leaf plates are often symptoms of disease or mineral deficiency. Some elements, such as iron, potassium, magnesium and nitrogen (the last two are directly in the chlorophyll molecule) necessary for the formation of chlorophyll, because these elements are particularly important $[1,4,9,12]$. Moreover, the cause of chlorosis may be a lack of light, because light is necessary in the final stage of chlorophyll synthesis [7, 9, 12].

The aim of the study. The aim of our study was to investigate the dynamics of chlorophyll "a" and "b» and carotenoids «k» in leaves of tomato (Lycopersicon esculentum Mill.) In six promising hybrids KDS-5 F1 $(\mathrm{K})$, Aeneas F1, Barmalei F1, take F1, YatranF1, rainbow F1 during the growing season in the main phases of development: budding, flowering, fruiting in terms of greenhouses. 
1.Vmist chlorophyll "a" and «b» and carotenoids in leaves hybrids F1pomidora (mg/g wet weight)

\begin{tabular}{|c|c|c|c|c|c|c|}
\hline \multirow{2}{*}{ Hybrids } & \multicolumn{4}{|l|}{ chlorophyll } & \multirow{2}{*}{ Carotenoids } & \multirow{2}{*}{$\frac{\mathrm{Xл.} \mathrm{a}+\mathrm{b}_{\text {Carotenoids }}}{\text { Caris }}$} \\
\hline & $a$ & $\mathrm{~b}$ & $\sum a+b$ & $a / b$ & & \\
\hline \multicolumn{7}{|c|}{ The phases of plant growth and development - budding } \\
\hline KDC-5 F1 (к) & $1,03 \pm 0,02$ & $0,48 \pm 0,03$ & $1,51 \pm 0,03$ & $2,14 \pm 0,02$ & $0,44 \pm 0,04$ & $3,43 \pm 0,04$ \\
\hline Aeneas F1 & $0,83 \pm 0,03$ & $0,44 \pm 0,02$ & $1,27 \pm 0,02$ & $1,89 \pm 0,02$ & $0,46 \pm 0,03$ & $2,76 \pm 0,04$ \\
\hline Barmalei F1 & $1,72 \pm 0,02$ & $1,11 \pm 0,03$ & $2,83 \pm 0,03$ & $1,55 \pm 0,02$ & $0,86 \pm 0,04$ & $3,29 \pm 0,03$ \\
\hline Colleague F1 & $1,02 \pm 0,03$ & $0,42 \pm 0,02$ & $1,44 \pm 0,02$ & $2,43 \pm 0,02$ & $0,49 \pm 0,04$ & $2,93 \pm 0,03$ \\
\hline Yatran F1 & $1,36 \pm 0,02$ & $0,58 \pm 0,03$ & $1,94 \pm 0,03$ & $2,35 \pm 0,02$ & $0,58 \pm 0,03$ & $3,35 \pm 0,04$ \\
\hline Rainbow F1 & $0,82 \pm 0,03$ & $0,42 \pm 0,02$ & $1,24 \pm 0,02$ & $1,95 \pm 0,02$ & $0,40 \pm 0,04$ & $3,10 \pm 0,03$ \\
\hline \multicolumn{7}{|c|}{ The phases of plant growth and development - blooming } \\
\hline KDC-5 F 1 (K) & $3,01 \pm 0,02$ & $1,08 \pm 0,02$ & $4,09 \pm 0,02$ & $2,79 \pm 0,02$ & $0,79 \pm 0,03$ & $5,18 \pm 0,03$ \\
\hline Aeneas F1 & $2,80 \pm 0,03$ & $0,98 \pm 0,03$ & $3,78 \pm 0,02$ & $2,86 \pm 0,02$ & $0,76 \pm 0,03$ & $4,97 \pm 0,02$ \\
\hline Barmalei F1 & $3,12 \pm 0,02$ & $1,24 \pm 0,02$ & $4,36 \pm 0,03$ & $2,52 \pm 0,02$ & $0,77 \pm 0,02$ & $5,67 \pm 0,02$ \\
\hline Colleague F1 & $2,90 \pm 0,02$ & $1,24 \pm 0,03$ & $4,14 \pm 0,03$ & $2,16 \pm 0,02$ & $0,69 \pm 0,02$ & $6,14 \pm 0,03$ \\
\hline Yatran F1 & $3,09 \pm 0,02$ & $1,20 \pm 0,02$ & $4,29 \pm 0,03$ & $2,57 \pm 0,02$ & $0,78 \pm 0,02$ & $5,50 \pm 0,02$ \\
\hline Rainbow F1 & $2,72 \pm 0,03$ & $1,01 \pm 0,02$ & $3,73 \pm 0,03$ & $2,70 \pm 0,03$ & $0,74 \pm 0,02$ & $5,04 \pm 0,03$ \\
\hline \multicolumn{7}{|c|}{ The phases of plant growth and development - bearing } \\
\hline KDC-5 $F_{1}$ (K) & $2,78 \pm 0,02$ & $1,19 \pm 0,03$ & $3,97 \pm 0,03$ & $2,33 \pm 0,02$ & $0,74 \pm 0,03$ & $5,36 \pm 0,03$ \\
\hline Aeneas F1 & $2,60 \pm 0,02$ & $1,08 \pm 0,02$ & $3,68 \pm 0,02$ & $2,41 \pm 0,03$ & $0,71 \pm 0,02$ & $5,18 \pm 0,02$ \\
\hline Barmalei F1 & $3,10 \pm 0,03$ & $1,21 \pm 0,03$ & $4,31 \pm 0,02$ & $2,56 \pm 0,02$ & $0,70 \pm 0,02$ & $6,16 \pm 0,03$ \\
\hline Colleague F1 & $2,70 \pm 0,02$ & $1,19 \pm 0,02$ & $3,89 \pm 0,03$ & $2,27 \pm 0,02$ & $0,72 \pm 0,02$ & $5,41 \pm 0,03$ \\
\hline Yatran F1 & $2,85 \pm 0,02$ & $1,19 \pm 0,03$ & $4,04 \pm 0,03$ & $2,45 \pm 0,02$ & $0,75 \pm 0,03$ & $5,35 \pm 0,02$ \\
\hline Rainbow F1 & $2,44 \pm 0,02$ & $0,78 \pm 0,02$ & $3,22 \pm 0,02$ & $3,13 \pm 0,03$ & $0,81 \pm 0,03$ & $3,97 \pm 0,02$ \\
\hline
\end{tabular}


Location and method of research. Experiments were carried out on the territory of NDP "Produce Garden" in film greenhouses, under the "Research Methodology in case of Vegetables and Melons" [3]. Area accounting area $-5 \mathrm{~m} 2$. Experiment embedded in 4-fold repetition. Scheme plants - $60 \mathrm{~h} 30 \mathrm{~cm}$, the number of plants per $1 \mathrm{~m} 2-5.5 \mathrm{pc}$. Statistical analysis of the data obtained was performed according to the method described BA Armor (1986) and processed using the program Microsoft Office Excel [5]. The content of photosynthetic pigments in leaves of tomato hybrids investigated were determined by the standard technique for scanning spectrophotometer OPTIZEN POP (South Korea). The content of chlorophyll "a" and «b» in the leaves of plants hybrids determined by different wavelengths (chlorophyll a) $662 \mathrm{~nm}$ (chlorophyll b) 644nm, carotenoids «k» 440 and $644 \mathrm{~nm}$. The concentration (C) pigments transferred in $\mathrm{mg}$ per $\mathrm{g}$ wet weight leaves the formulas HN Pochynka [11]:

$$
\begin{aligned}
& C_{a}=9,78 * D_{662}-0,99 * D_{644} \\
& C_{b}=21,43{ }^{*} D_{644}-4,65{ }^{*} D_{662} \\
& C_{a}+C_{b}=5,13{ }^{*} D_{662}+20,44{ }^{*} D_{644} \\
& C_{k}=4,7{ }^{*} D_{440}-\left(1,38 *{ }^{*} D_{662}+5,48{ }^{*} D_{644}\right)
\end{aligned}
$$

where: Ca - concentration CL "a», Cb- concentration CL «b», Ck- concentration of carotenoids, D440optical density of the mixture at a wavelength of $440 \mathrm{~nm}$, D662- extract absorbance at $662 \mathrm{~nm}$ wavelength, D644- optical density of the extract at a wavelength of $644 \mathrm{~nm}$. All experiments were performed in fourfold repetition, the results worked out statistically. Growing seedlings in cassettes: hybrid tomato seedlings were grown in a glass greenhouse winter Department of Dendrology and Landscape Architecture NUBiP Ukraine. Seeds of tomato hybrids studied were seeded 13-15 March cassette. Seedlings grown in cassettes containing 35 cells, size $50 \times 40 \mathrm{~cm}$. For permanent hybrid seedlings planted in phase $6-7$ true leaves aged 40 days under that scheme placement of plants.

Results. Found that during the study, chlorophyll "a" and «b» and carotenoids in the early growing season was marked slow accumulation of pigments, but the flowering phase since the rate of accumulation of pigments increased. In a phase fruiting accumulation of pigments decreased significantly (Table. 1). Established that the leaves of tomato F1 hybrids Barmalei F1, F1 Yatran contained the largest number of chlorophyll: the budding ("a" -1.72 and $1.36 \mathrm{mg} / \mathrm{g}$ wet weight, «b» $-1,11$ and $0.58 \mathrm{mg} / \mathrm{g}$ wet weight); a phase of flowering ("a" -3.12 and $3.09 \mathrm{mg} / \mathrm{g}$ wet weight, «b» $-1,24$ and $1.20 \mathrm{mg} / \mathrm{g}$ wet weight); a phase of fruition ("a" - 3.10 and $2.85 \mathrm{mg} / \mathrm{g}$ wet weight, «b» $-1,21$ and $1,19 \mathrm{mg} / \mathrm{g}$ wet weight). Performance control variant hybrid KDS-5 F1 (k) contained slightly smaller number of chlorophylls "a" and «b»: budding - 1.03 and 0.48 $\mathrm{mg} / \mathrm{g}$ wet weight; flowering -3.01 and $1.08 \mathrm{mg} / \mathrm{g}$ wet weight; fruiting -2.78 and $1.19 \mathrm{mg} / \mathrm{g}$ wet weight. The least amount of chlorophyll "a" and «b» is fixed in F1 hybrid rainbow in all the three phases of growth and development "and" - 0.82; 2.72; 2.44; «B» - 0,42; $1.01 ; 0.78 \mathrm{mg} / \mathrm{g}$ wet weight.

The biggest amount of chlorophyll content differed Barmalei F1 hybrid plants and made: in the budding phase - 2.83, which control more than option at $87.4 \%$; flowering - 4.36, which control more than $6.7 \%$; fruiting - 4.31 , which control more than $8.6 \%$. The lowest rates in Rainbow F1 hybrid plants at three stages of growth and

\begin{tabular}{|c|c|c|c|c|c|c|}
\hline \multirow[b]{3}{*}{ Hybrids } & \multicolumn{6}{|c|}{ The phases of plant growth and development } \\
\hline & \multicolumn{2}{|l|}{ budding } & \multicolumn{2}{|l|}{ flowering } & \multicolumn{2}{|c|}{ fruiting } \\
\hline & $\begin{array}{l}\mathrm{mg} / \mathrm{g} \\
\text { wet weight }\end{array}$ & $\%$ Of control & $\begin{array}{l}\mathrm{mg} / \mathrm{g} \\
\text { wet weight }\end{array}$ & $\%$ Of control & $\begin{array}{l}\text { mg/g } \\
\text { wet } \\
\text { weight }\end{array}$ & $\%$ Of control \\
\hline KDC-5 F1 (к) & 1,51 & 100,0 & 4,09 & 100,0 & 3,97 & 100,0 \\
\hline Aeneas F1 & 1,27 & 84,2 & 3,78 & 92,5 & 3,68 & 92,7 \\
\hline Barmalei F1 & 2,83 & 187,4 & 4,36 & 106,7 & 4,31 & 108,6 \\
\hline Colleague F1 & 1,44 & 95,4 & 4,14 & 101,3 & 3,89 & 98,0 \\
\hline Yatran F1 & 1,94 & 128,4 & 4,29 & 104,9 & 4,04 & 101,7 \\
\hline Rainbow F1 & 1,24 & 83,0 & 3,73 & 91,2 & 3,22 & 81,1 \\
\hline
\end{tabular}
development were in the range: 1.24 - 3.73, which is less than the control DPT-5 F1 (k) 18,9-8,8\% (Table. 2).

\section{Vplyv method of growing seedlings, the chlorophyll content of the sum of "a" and «b» in leaves of tomato F1 hybrids}


Value chlorophyll "a" chlorophyll to "b» is an indicator functionality pigment composition and light adaptation of the photosynthetic apparatus (Table. 1). The influence of different factors causing the change ratio of chlorophyll $\mathrm{a} / \mathrm{b}[13,14,15]$. F1 hybrids of tomato plants, photosynthesis which occurs in normal conditions, contain more chlorophyll a than chlorophyll $b$, ie the ratio of chlorophyll $a / b$ normally greater than 1. Reduction of indicated value to less than 1 indicates a violation of the photosynthetic system and points the predominance of degradation processes of organic matter over the processes of synthesis [13]. Changing the chlorophyll is mainly due to the lability of chlorophyll "a". In plants that grow in terms of eclipse, chlorophyll ratio lower than the light-loving plants. Theoretically considered optimal ratio of chlorophyll $a / b$ in 2,5-2,9 Shade plants in sun-3,2-4,0 [14, 15].

It was established that the maximum value for all variants of chlorophyll a phase of flowering, which ranged from 2.16 (brother F1) to 2.86 (Aeneas F1). The minimum value characteristic plants of all options in the budding phase, and it ranged from 1.55 (Barmalei F1) to 2.43 (brother F1). The results indicate that the plants Lycopersicon esculentum Mill. is high light, they are able to effectively use light energy due to the concentration of chlorophyll.

The content of carotenoids in the investigated hybrids during the observation was within: the budding - 0 , $40-0,86 \mathrm{mg} / 100 \mathrm{~g}$ wet weight; flowering $-0,69-0,79 \mathrm{mg} / 100 \mathrm{~g}$ wet weight; fruiting $-0,70-0,81 \mathrm{mg} / 100 \mathrm{~g}$ wet weight.

The study correlation between the amount of chlorophyll and carotenoids in tomato hybrids for different growing season revealed that most of carotenoids to chlorophyll ratio observed in $\mathrm{F} 1$ hybrid cousins in the phase of fruiting - 6.16, the lowest in hybrid Aeneas F1 - 2,76. For other tomato F1 hybrids characterized by minor changes during the growing season. In general, the ratio between the amount of chlorophyll and carotenoids was within: in the budding phase - 2.76 - 3.43; flowering - 4,97- 6,14; fruiting - 3,97-6,16.

\section{Conclusions.}

Summing up the results of the research the following conclusions. Found that the best way of growing seedlings are tape. It is shown that the quantitative fotosentytychnyh pigments in the leaves of the investigated culture (Lycopersicon esculentum Mill.) Grown in greenhouses on sunny heating medium. Established that parameters pigment composition in leaves Barmalei hybrid F1, take F1, F1 Yatran are higher compared to other studied hybrids F1, which may indicate, the highest potential of adaptive data hybrids for these conditions greenhouses.

\section{Bibliography}

1. Andrianova S. Chlorophyll and performance of plants/Andrianova YS, Tarchevskyy I. A. M .: Science, 2000, 136 pp.

2. Vegetable Barabash OY/OY Barabash. - K .: High School, 1994. - 373 p.

3. Bondapenka G.L Metodyka research sppavy in ovochivnytstvi i bashtannytstvi/for red.H.L. Bondapenka, K.I. Yakovenka. - Kharkiv Osnova .:, 2001. - 369 p.

4. Gavrylenko VF Bolshoi workshop on fyzyolohyy plants. Photosynthesis/VF Gavrilenkov, M.E Ladbhyna, LM Handobyna. - M .: Higher School, 1975. - 392 p.

5. armor B.A Methods polevoho Experience/BA Armor. - M .: Agropromizdat, 1985. - 351 p.

6. Kyryzyy DA Aktseptorov assymylyatov role in photosynthesis and rehulyatsyy apportionment of carbon in plants /D.A. Kyryzyy//Fyzyolohyya cultural and biochemistry of plants. -2003. - T.35. -№5. - 282-391 p.

7. Kosakivsky IV Physiological and biochemical bases of plant adaptation to stress. I

IV Kosakivsky - K .: Steel, 2003. - $192 \mathrm{p}$.

8. Musienko M. Plant Physiology. Workshop./M. Musienko. - Kiev, 1995. - 191 p.

9. Nychyporovych A. Activities Fotosyntetycheskaya plants and path $s$ Increase productivity. Monohrafyya/AA Nychyporovych. - M .: 1972. - 511-527 p.

10. Vegetable and fruit growing. Tutorial. - K.Vyscha HQ., 2000. - 503 p.

11. Pochinok H.N. Methods of analysis biochemically plants/H.N. Pochinok. - K .: Naukova Dumka, 1976. $-333 p$.

12. VF Pivovarov Paslenovыe culture: tomato, pepper, eggplant, fyzalys/VF Pivovarov, M.Y.Mamedov, NI Bocharnykova - M., 1998. - 293 p. 
13. AA Shluk Determination of chlorophyll and carotenoids in эkstraktah zelenth lystev/AA Shlok//Byohymycheskye fyzyolohyy methods in plants. - M .: Nauka, 1971. - pp 154-170.

14. Scheer H. Chlorophylls and sarotenoids in: Encyclopedia of Biological Chemistry/H. Scheer.- 2004. P. 430-437.

15. Photosynthetic activity, chloroplast ultrastructure, and leaf characteristics of high-light and low-light plants and of sun and shade leaves/H .K. Lichtenthaler, C. Buschmann, M. Döll, et al.//Photosynthesis Res. 1981. - Vol. 2, No 2. - R. 115- 141. 